\title{
ANÁLISE SOCIOAMBIENTAL NO PÓLO DE JEREMOABO-BA: RELAÇÃO ENTRE DESERTIFICAÇÃO E DESIGUALDADE SOCIOECONÔMICA NO SERTÃO SEMIÁRIDO
}

\section{$\underline{\text { Carine Fonseca Menezes Silva1; }}$; Nacelice Barbosa Freitas ${ }^{2}$; Aryane Sinval Alves ${ }^{3}$}

1. Bolsista PIBIC/PROBIC, Graduando em Geografia da Universidade Estadual de Feira de Santana, e-mail:

$$
\text { carinemeneze@gmail.com }
$$

2. Orientador, Departamento de Ciências Humanas e Filosofia, Universidade Estadual de Feira de Santana, e-mail: nacegeografic@provedor.br

3. Participante do Grupo de Pesquisa em Natureza, Sociedade e Ordenamento Territorial, Departamento de Ciências Humanas e Filosofia, Universidade Estadual de Feira de Santana, e-mail: aryansalves@ gmail.com

PALAVRAS-CHAVE: desertificação; desigualdades socioeconômicas; Pólo de Jeremoabo.

\section{INTRODUÇÃO}

A Convenção das Nações Unidas de Combate à Desertificação (CCD), indica que em climas áridos, semiáridos e sub-úmidas secas, ocorre o processo de desertificação, provocado pela degradação ambiental. O processo resulta também da ação antrópica, tais como, as formas inadequadas de uso e manejo do solo, nas atividades agrícolas e pastoris, desmatamento, queimadas etc.

O presente resumo apresenta o resultado da pesquisa de iniciação científica que teve como objetivo analisar a relação entre a desertificação e a desigualdade de distribuição de renda a partir dos indicadores socioeconômicos, dos municípios que integram o Pólo de Jeremoabo, tomando como referência o Produto Interno Bruto entre 2011 a 2015, o rendimento médio mensal entre 2011 a 2015, o Índice de Gini entre 2010 a 2015, a oferta de emprego, desemprego e subemprego entre 2010 a 2015.

\section{MATERIAL E MÉTODOS}

As regiões semiáridas segundo Silva (2007) são caracterizadas, pela semiaridez do clima, deficiência hídrica com imprevisibilidade das precipitações pluviométricas, e pela presença de solos pobres em matéria orgânica. A semiaridez sazonal é resultado do prolongado período seco anual que eleva a temperatura local.

O Pólo de Jeremoabo é constituído por treze municípios: Antas, Canudos, Chorrochó, Coronel João Sá, Glória, Jeremoabo, Macururé, Novo Triunfo, Paulo Afonso, Pedro Alexandre, Rodelas, Santa Brígida, e Uauá situados na área susceptível à desertificação (ASD). Mapa 1

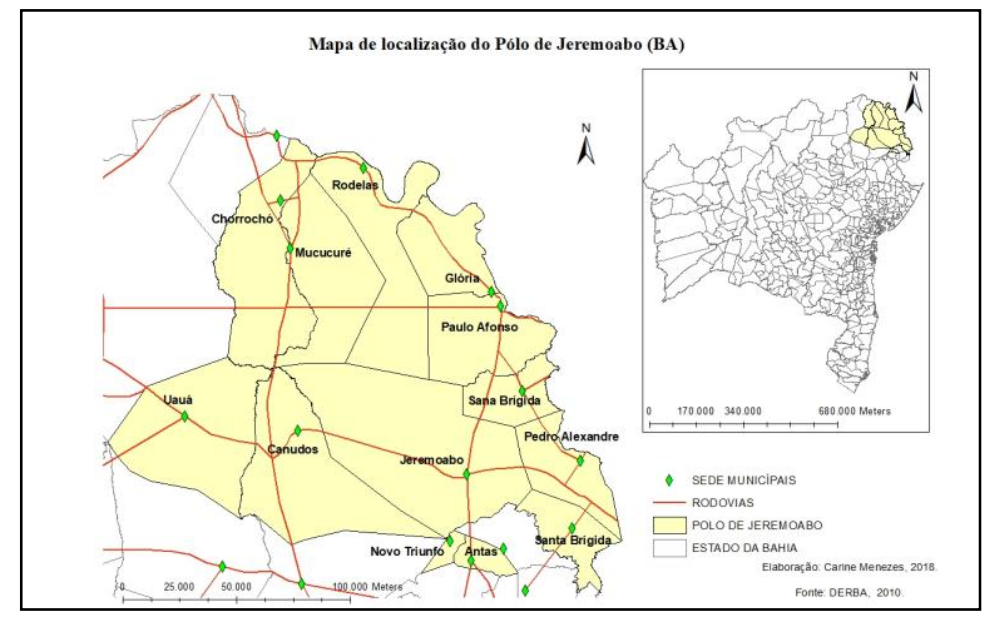

Mapa 1: Localização do Pólo de Jeremoabo no estado da Bahia 
Os municípios integram uma área localizada no Nordeste do Brasil, situada na parte norte da Bahia, correspondendo, portanto ao clima semiárido que tem como características básicas o índice pluviométrico entre 400 e $500 \mathrm{~mm} / \mathrm{ano}$, com temperaturas que não apresentam grande variabilidade anual gerando uma média de $26^{\circ} \mathrm{C}$.

Para produção da pesquisa, realizou-se o levantamento bibliográfico, visando a discussão sobre desertificação, semiárido, indicadores socioeconômicos e em seguida identificou-se os dados sociodemográficos em tabelas e gráficos para posteriormente mapear com a utilização do Sistema de Informações Geográficas (SIG).

$\mathrm{Na}$ elaboração dos mapas utilizou-se o software Arc View para o processamento de dados vetoriais e introdução dos dados tabulares e o Arc Map. Tal etapa possibilitou ter uma visão ampla da área de estudo, ao relacionar o mapeamento à evolução dos números, e correlacionar as informações obtidas ao conceito de qualidade de vida em Área Susceptível a Desertificação (ASD).

\section{RESULTADOS E/OU DISCUSSÃO}

Os municípios que integram o Pólo de Jeremoabo estão inseridos na região semiárida da Bahia, A população total dos municípios, segundo os dados do censo demográfico do Instituto Brasileiro de Geografia e Estatísticas (IBGE-2010), corresponde a 309.004 mil habitantes. A população rural registra $134.543 \mathrm{mil}$ habitantes, representando $43 \%$ da população total, enquanto a população urbana representa 57\%, somando 174.461 mil habitantes.

Neste item expõe-se os resultados propostos e alcançados durante a realização da pesquisa sobre a evolução dos números referentes aos indicadores socioeconômicos, no Pólo de Jeremoabo, observando a relação com o processo desertificação.

Analisando o Produto Interno Bruto (PIB) dos municípios que integram o Pólo de Jeremoabo, identifica-se que a agropecuária é o setor de menor expressividade quanto ao no ano de 2010. As atividades agropastoris caracterizam-se como a atividade de sustento para as famílias, além de $43 \%$ da população do Pólo está concentrada no espaço rural. Porém os preços correntes aplicados ao setor da agropecuária é inferior aos do setor industrial e de serviços.

O Produto Interno Bruto (PIB) corresponde a soma de toda riqueza produzida em um país, segundo os dados Instituto Brasileiro de Geografia e Estatística (IBGE). Os dados referentes ao PIB do Pólo de Jeremoabo em 2015 permitem analisar as desigualdades socioeconômicas entre os municípios, no intervalo estudado. Entre 2010 a 2015, apenas quatro municípios apresentaram PIB acima de 200 mil reais, sendo que Paulo Afonso é o município que tem o maior PIB devido aos rendimentos da CHESF. Mapa 2

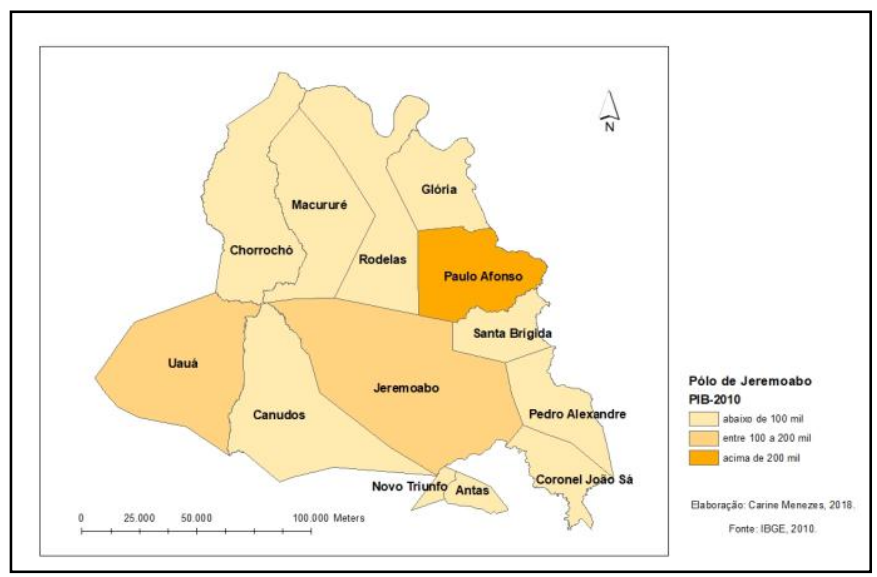

Mapa 2: Produto Interno Bruto do Pólo de Jeremoabo 2010 
Percebe-se que Paulo Afonso possui um dos maiores Produto Interno Bruto (PIB) do estado da Bahia, consequentemente o maior do Pólo de Jeremoabo. Os números resultam do fato de o setor secundário ser o principal responsável pela receita do município, devido a Companhia Hidroelétrica do São Francisco (CHESF).

Os dados referentes ao PIB do Pólo de Jeremoabo em 2015 permitem analisar as desigualdades socioeconômicas entre os municípios, no intervalo estudado. Entre 2010 a 2015, apenas quatro municípios apresentaram PIB acima de 200 mil reais, sendo que Paulo Afonso é o município que tem o maior PIB devido aos rendimentos da CHESF. MAPA 3

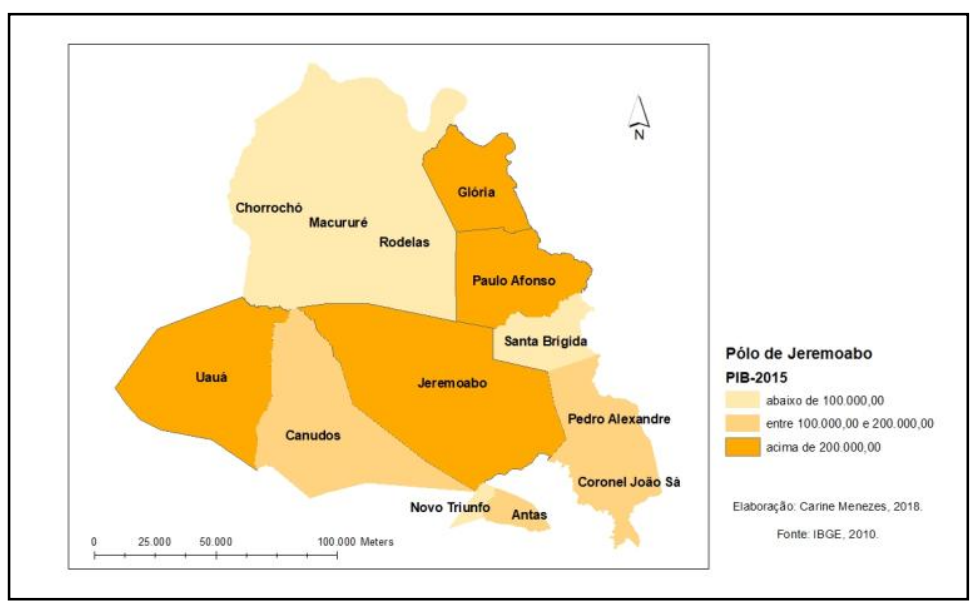

Mapa 3: Produto Interno Bruto do Pólo de Jeremoabo 2015

O Índice de Gini é um instrumento matemático utilizado para medir a desigualdade social de um determinado país, unidade federativa ou município. A medição do índice de Gini obedece a uma escala que vai de 0 (quando não há desigualdade) a 1 (com desigualdade máxima), dois números cujos valores jamais serão alcançados por nenhum lugar, pois representam extremos ideais. Nesse sentido, quanto menor é o valor numérico do coeficiente de Gini, menos desigual é um país, estado, ou município e vice-versa.

Os municípios de Chorrochó, Macururé, Rodelas, Glória e Paulo Afonso são os que segundo o índice apresentam menos desigualdade, enquanto Uauá, Canudos, Jeremoabo e Santa Brígida apresentam índice entre 0,35 a 0,40. Os municípios que mais apresentaram desigualdades foram os de Pedro Alexandre, Coronel João Sá, Novo Triunfo e Antas. Mapa 4

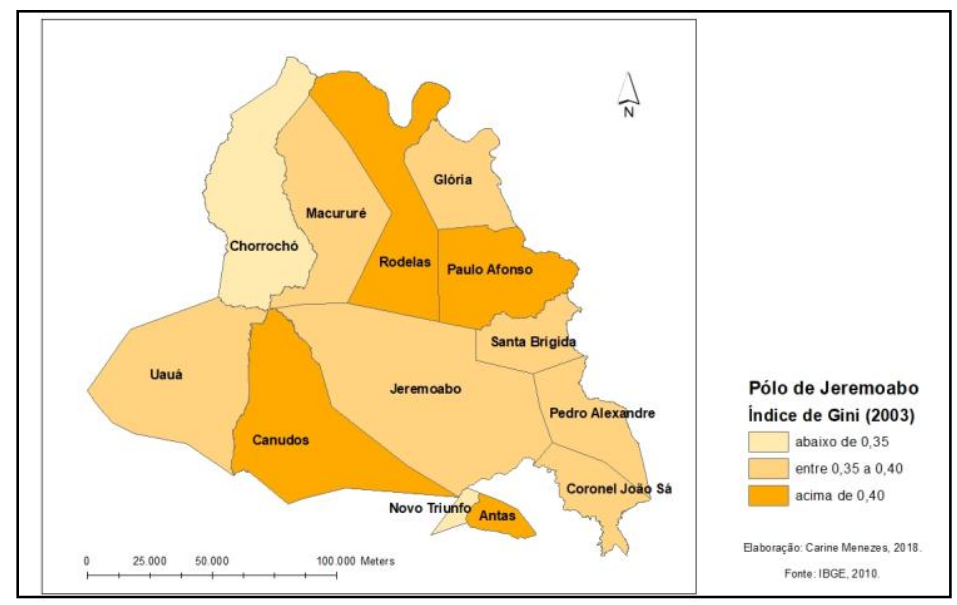

Mapa 4: Índice de Gini do Pólo de Jeremoabo 2003 
O mapa 4 apresenta a Incidência de Pobreza do Pólo de Jeremoabo e reforça a necessidade políticas públicas voltadas para a população do sertão semiárido nordestino, apenas o município de Chorrochó apresentou índices abaixo de 0,35, Macururé e Rodelas entre 0,35 e 0,40, enquanto Glória, Paulo Afonso, Uauá, Canudos, Jeremoabo, Pedro Alexandre, Novo Triunfo, Coronel João Sá e Antas apresentam Incidência de Pobreza acima de 0,40 .

É evidente que as desigualdades socioeconômicas do sertão semiárido é resultado da vulnerabilidade ambiental e ausência de políticas públicas prioritárias para minimizar os efeitos da desertificação no Pólo de Jeremoabo.

\section{CONSIDERAÇÕES FINAIS}

A pesquisa teve como objetivo explicar a evolução dos números referentes aos indicadores socioeconômicos, no Pólo de Jeremoabo, explicando a relação com o processo de desertificação, com o intuito de subsidiar os estudos sobre ordenamento territorial em região de clima semiárido.

A vulnerabilidade ambiental ao processo de desertificação configura-se como uma problemática para a administração dos municípios. Conclui-se que a distribuição espacial da população do Pólo explica a importância da agropecuária para o sustento das famílias, dos treze municípios que compõem o Pólo de Jeremoabo, enquanto onze apresentam uma população residente no espaço rural superior aos residentes do espaço urbano.

Observando os números referentes aos Indicadores Socioeconômicos percebese que o PIB dos municípios teve um aumento de 5\% entre 2010 a 2015, em termos geral o PIB de 2015 é cerca de 25\% maior que o Produto Interno Bruto de 2010.

Segundo o Índice de Gini os municípios que mais apresentaram desigualdades no Pólo de Jeremoabo foram os de Pedro Alexandre, Coronel João Sá, Novo Triunfo e Antas, enquanto os de maior incidência de pobreza foram Glória, Paulo Afonso, Uauá, Canudos, Jeremoabo, Pedro Alexandre, Novo Triunfo, Coronel João Sá e Antas. O cenário reflete as consequências do processo de desertificação, que interfere na produção agrícola, reforçando a necessidade de políticas públicas para a melhoria da qualidade de vida de seus habitantes.

Dessa forma, a pesquisa busca oferecer informações que sirvam de instrumentos para o ordenamento territorial, definição de políticas públicas especificas para áreas de vulnerabilidade, tendo em vista que a explicação sobre desertificação do sertão e semiárido possibilita uma reflexão acerca das desigualdades sociais no semiárido baiano, pois sabe-se que tais aspectos alimentam os discursos socialmente construídos originando um imaginário social, pois este espaço é visto, principalmente pela mídia, como o território da seca, da pobreza, e da exclusão social.

\section{REFERÊNCIAS}

AB'SÁBER, A. Os domínios de natureza no Brasil: potencialidades paisagísticas. São Paulo: Ateliê Editorial, 2003.

BRASIL, Ministério do Meio Ambiente. Programa Nacional de Combate à Desertificação e Mitigação dos Efeitos da Seca PAN-Brasil. Brasília, DF: Ministério do Meio Ambiente; Secretaria de Recursos Hídricos, 2005.

MALVEZZI, Roberto. Semiárido - uma visão holística. - Brasília: C onfea, 2007.

SILVA, Roberto Marinho Alves da. Entre dois Paradigmas: Combate a seca e convivência com o Semi-Árido. Sociedade e Estado, Brasília, v. 18, n. 1/2, p. 361-385, jan./dez. 2003 